\title{
Self-Healing Hydrogels Based on Sodium Carboxymethyl Cellulose/Poly(vinyl alcohol) Reinforced with Montmorillonite
}

\author{
Nicharee Weerawan $^{1(\mathbb{D})}$, Jongjit Chalitangkoon ${ }^{1}(\mathbb{D})$, Pathavuth Monvisade 1 1* (D) \\ 1 Polymer Synthesis and Functional Materials Research Unit, Department of Chemistry, School of Science, King Mongkut's \\ Institute of Technology Ladkrabang, Chalong Krung Road, Ladkrabang, Bangkok 10520, Thailand; \\ pathavuth.mo@kmitl.ac.th (P.M.); \\ * Correspondence: pathavuth.mo@kmitl.ac.th (P.M.);
}

Scopus Author ID 18133833400

Received: 11.08.2021; Revised: 18.09.2021; Accepted: 23.09.2021; Published: 16.10.2021

\begin{abstract}
Currently, self-healing hydrogels prepared from the green process have been studied for various applications, especially in the biomedical field. This work fabricated the self-healing hydrogel based on sodium carboxymethyl cellulose/poly(vinyl alcohol)/montmorillonite by acidifying the mixture with citric acid. SEM measurements showed well-dispersed montmorillonite in the hydrogels. Cytotoxicity values $>100 \%$ were seen with montmorillonite added, which indicated cell growth and no cell toxicity. Montmorillonite addition not only reinforced the networks but also improved self-healing ability. The tensile strength of the original uncut hydrogel with montmorillonite (P1C8M1) was $61 \mathrm{kPa}$, whereas the healed hydrogel showed $57 \mathrm{kPa}$. The hydrogel healed completely within 10 days, without any cracks, i.e., a $93 \%$ healing efficiency, or higher than the $\sim 60 \%$ of the non-reinforced hydrogel. This confirmed strong hydrogen bond formation between the polymer and montmorillonite. The self-healing ability of this non-toxic hydrogel, reinforced with montmorillonite, makes it valuable for use in biomedical fields.
\end{abstract}

Keywords: self-healing hydrogel; hydrogen bond; sodium carboxymethyl cellulose; montmorillonite; poly(vinyl alcohol).

(C) 2021 by the authors. This article is an open-access article distributed under the terms and conditions of the Creative Commons Attribution (CC BY) license (https://creativecommons.org/licenses/by/4.0/).

\section{Introduction}

Soft smart materials are attractive because they can respond to multiple stimuli, for example, stress, light, temperature, moisture, $\mathrm{pH}$, and electric or magnetic fields, and form useful functions - like sensors, actuators, bioreactors, drug delivery systems, and cell culture systems [1,2]. Hydrogels, three-dimensional networks of cross-linked hydrophilic polymers, have become a useful platform for smart material fabrication because of their biocompatibility, high water content, non-irritability, and structural similarity to natural extracellular matrices [3]. Hydrogels have been applied in, for example, tissue engineering [4], wound dressing [5], drug delivery [6, 7], and health-monitoring systems [8, 9].

Recently, self-healing hydrogels have been used in various fields due to their intrinsic damage recovery [10]. They can be formed by reversible interactions, including dynamic covalent bonds [11], hydrogen bonds [12], ionic bonds [13], and hydrophobic interaction [14]. For non-covalent hydrogels, the cross-linking points are easily randomly reversible, but mechanical strengths are relatively low [15]. Nanocomposite gels with inorganic fillers, e.g., 
clay, graphene oxide, and cellulose nanofibers, effectively improve mechanical properties [16]. These particles can cross-link with the polymer matrix via physical interactions, which improve the mechanical property and self-healing ability [17-19].

Montmorillonite (MMT), a natural mineral, has stacked layers of aluminum octahedrons and silicon tetrahedrons, where oxygen atoms on the cell boundaries form hydrogen and ionic bonds to link the layers [20]. Due to its high surface area and surface reactivity, MMT has been used in polymers as an adsorbent [21, 22]. Moreover, MMT is often used to fabricate nanocomposite materials because it showed good dispersion in the polymer matrix and the ability to dissipation energy [23, 24].

Sodium carboxymethyl cellulose (CMC), a water-soluble cellulose derivative, is a polysaccharide derived from abundant natural sources, with the benefit of biocompatibility, biodegradability, nontoxicity, and low cost [25]. CMC is an attractive natural material to fabricate hydrogels for many applications, including wound dressing, tissue engineering, and drug delivery [26]. To create a self-healing CMC hydrogel, physical cross-links, with hydrogen bonds [27] or ionic interactions [28], and chemical cross-links, e.g., phenyl boronate ester bonds [29] have been described. However, CMC hydrogels, reinforced with MMT, have not been reported.

PVA, a synthetic polymer with several hydroxyl groups in its structure, can easily form hydrogen bonds with neighboring molecules. It has been used for biomedical applications because of its biocompatibility and nontoxicity [30, 31]. The addition of PVA in hydrogels recipe can enhance their mechanical properties $[32,33]$. Here, we report self-healing hydrogels, based on CMC and PVA, reinforced by MMT. The CMC/PVA/MMT-based hydrogels were prepared by acidifying the mixture with citric acid to form strong hydrogen bonds. The morphology, mechanical properties, and cytotoxicity of the obtained hydrogels were examined. Their self-healing ability and efficiency for biomedical fields were also investigated.

\section{Materials and Methods}

\subsection{Materials.}

Sodium carboxymethyl cellulose powder (CMC, M.W. 90,000, DS=0.7) was purchased from Acros Organic Co., Ltd. Poly(vinyl alcohol) (PVA, viscosity = 4.0-6.0 mPa.s, hydrolysis $<98.5 \%$ ) was purchased from Nippon Gohsei, Japan. Montmorillonite (MMT, 200 mesh, cation exchange capacity (CEC) $1 \mathrm{meq} / \mathrm{g}$ ) was supplied by the Thai Nippon Chemical Industry. Citric acid and sodium benzoate were obtained from Carlo Erba Co., Ltd.

\subsection{Preparation of PCM hydrogels.}

MMT suspension stocks at $0.1,0.5$, and $1 \% \mathrm{w} / \mathrm{v}$ were prepared by dispersing MMT in distilled water at $25^{\circ} \mathrm{C}$ for $30 \mathrm{~min}$ and further sonicated for $30 \mathrm{~min}$. PVA at measured amounts was dissolved in $30 \mathrm{~mL}$ MMT suspension with vigorous stirring at $90^{\circ} \mathrm{C}$ (PVA-MMT portion). Measured amounts of CMC powder were dissolved in $70 \mathrm{~mL}$ MMT suspension (CMC-MMT portion). The PVA-MMT part was then added into the CMC-MMT portion and stirred for 2 $\mathrm{h}$, and $0.1 \mathrm{~g}$ of sodium benzoate was subsequently added. The viscous PVA-CMC-MMT mixture was centrifuged at $5000 \mathrm{rpm}$ for $10 \mathrm{~min}$ to release air bubbles and then poured into silicone molds before immersing into citric acid $(8 \mathrm{~mol} / \mathrm{L})$ for $3 \mathrm{~h}$, which the PVA-CMC-MMT hydrogel (formulae 4-6) could set following Zheng et al. [27]. A similar method was used to prepare PVA-CMC hydrogels (formulae 1-3): PVA was dissolved in $30 \mathrm{~mL}$ water at $90^{\circ} \mathrm{C}$, and 
CMC powder was dissolved in $70 \mathrm{~mL}$ water at room temperature. The PVA solution was added to the CMC solution and stirred for $2 \mathrm{~h}$, following the same manner with formulae 4-6. The hydrogel formulae are shown in Table 1.

Table 1. Hydrogel formulae.

\begin{tabular}{l|l|l|l}
\multirow{2}{*}{ Formulae } & \multicolumn{3}{|c}{ Concentration $(\% \mathbf{w} / \mathbf{v})$} \\
\cline { 2 - 4 } & PVA (P) & CMC (C) & MMT (M) \\
\hline P1C8 & 1 & 8 & - \\
\hline P2C8 & 2 & 8 & - \\
\hline P3C8 & 3 & 8 & - \\
\hline P1C8M0.1 & 1 & 8 & 0.1 \\
\hline P1C8M0.5 & 1 & 8 & 0.5 \\
\hline P1C8M1 & 1 & 8 & 1
\end{tabular}

\subsection{Scanning electron microscope (SEM).}

The dispersion of MMT within the hydrogels was examined by a scanning electron microscope, using low vacuum mode, without sputtered $\mathrm{Au}, 7.50 \mathrm{kV}$, at $800 \times$ magnification. Morphology and pore sizes of the hydrogels were recorded by scanning electron microscopeenergy dispersive spectrometry (SEM-EDS, Quanta 250, FEI, USA). The samples were prepared by freezing at $-40^{\circ} \mathrm{C}$ and then freeze-dried: these samples were sputter-coated with $\mathrm{Au}$.

\subsection{Mechanical property testing.}

Mechanical properties of the hydrogels were measured by a universal testing machine (UTM, Lloyd Instruments). Rectangular, $30 \times 78 \times 3 \mathrm{~mm}^{3}$ samples were prepared for tensile testing and with a size of $20 \times 20 \times 10 \mathrm{~mm}^{3}$ for compressive testing. Tensile and compressive testing used a $100 \mathrm{~N}$ load cell and tested at $10 \mathrm{~mm} / \mathrm{min}$. Samples were conditioned at $90 \pm 5 \%$ relative humidity; the atmosphere was created by a beaker of water at $25{ }^{\circ} \mathrm{C}$ in the sample chamber for 10 days before testing and measured at $25^{\circ} \mathrm{C}$.

\subsection{Self-healing assessment.}

The healing efficiency of the hydrogels was determined by cutting samples into two pieces by a scalpel. After that, these two pieces were reattached and conditioned at $90 \pm 5 \%$ relative humidity. The tested samples were monitored at $0,1,5$, and 10 days to measure healing efficiency. The healing efficiency was calculated by:

$$
\text { Healing efficiency }(\%)=\frac{s_{h}}{S_{i}} \times 100
$$

where $S_{h}$ and $S_{i}$ are the stresses at the maximum load of the healed and the initial hydrogels.

\subsection{Cytotoxicity assay (MTT assay).}

MTT assays evaluated in vitro cytotoxicity of the hydrogels [34]. Firstly, the hydrogel samples were soaked in phosphate buffer at $37^{\circ} \mathrm{C}$ for $24 \mathrm{~h}$. The liquor was filtered through a sterilized syringe filter, $0.2 \mu \mathrm{m}$ pore size, and stored in sterilized Duran bottles. The liquid was subsequently exposed to Dulbecco's Modified Eagle Medium (DMEM). African green monkey kidney fibroblast (Vero) cultures were seeded in a 96-well plate with $100 \mu \mathrm{l} /$ well and incubated $\left(37^{\circ} \mathrm{C}, 24 \mathrm{~h}\right)$. The extracted sample was then added to each plate and incubated $\left(37^{\circ} \mathrm{C}, 24 \mathrm{~h}\right)$. $10 \mu \mathrm{l} 5 \mathrm{mg} / \mathrm{ml}$ MTT solution was later added to each well and further incubated $\left(37^{\circ} \mathrm{C}, 4 \mathrm{~h}\right)$. 
The cell viability was determined by a microplate reader, which measured absorbance at 570 nm. Cytotoxicity was calculated from:

$$
\text { Cytotoxicity }(\%)=\left(\frac{A-B}{A}\right) \times 100
$$

where $\mathrm{A}$ is the absorbance of the control cell and $\mathrm{B}$ is the absorbance of the sample solution.

\subsection{Statistical analysis.}

The statistical analysis used Minitab 18 software. The means were determined by oneway analysis of variance, and a Tukey test tested variances.

\section{Results and Discussion}

\subsection{Preparation of PCM hydrogels.}

PCM hydrogels were prepared by mixing measured amounts of PVA (1-3\% w/v), CMC $(8 \% \mathrm{w} / \mathrm{v})$, and MMT $(0.1-1 \% \mathrm{w} / \mathrm{v})$ and cross-linked by acidifying in citric acid $(8 \mathrm{M})$, where the viscous liquid solidified to form the hydrogel. Citric acid protons diffused into the mixture and interacted with CMC carboxylate groups, transformed into carboxylic groups. This functional group can form strong hydrogen bonds with hydroxyl groups of both CMC and PVA, and with carboxylic groups, themselves contributed to physical cross-linking of the polymer chains [35]. The hydroxyl and carbonyl groups of CMC and hydroxyl groups of PVA also formed hydrogen bonds with MMT silanol groups [36]. The mechanism of hydrogel formation is illustrated in Figure 1.

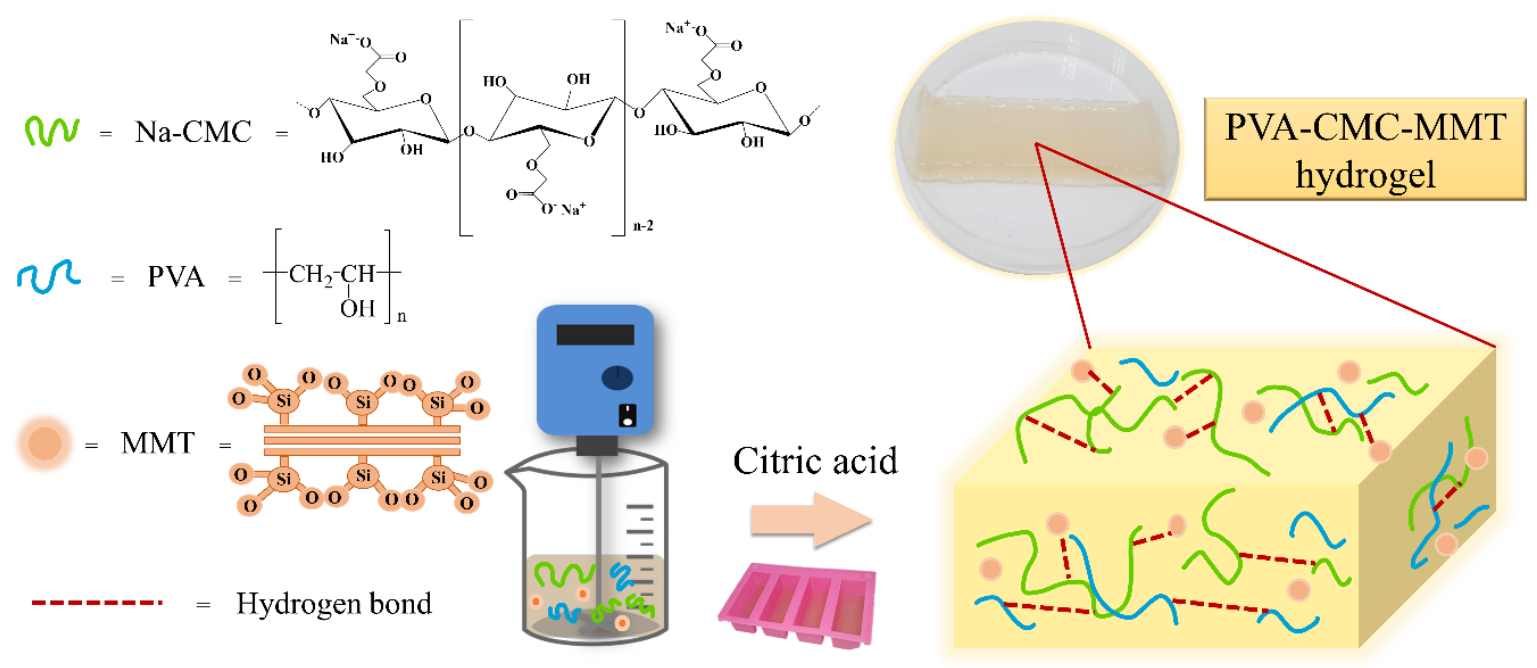

Figure 1. Schematic illustration of PCM hydrogel formation.

\subsection{Morphology analysis.}

The distribution of MMT in PCM hydrogel was investigated by SEM-EDS. The crosssection and mapping analysis of PCM hydrogel is in Figure 2. There was a good distribution of $\mathrm{Si}$ and $\mathrm{Al}$ atoms, indicating that MMT was successfully distributed throughout the hydrogel. The morphology of the dried PCM hydrogels was seen in SEM images. The samples were prepared in dry form by freeze-drying. 1000× magnifications of cross-sections were examined to determine pore sizes, which ranged from 21.9 to $24.0 \mu \mathrm{m}$ - see Figure 3. The pore wall thickness increased with MMT in the hydrogels: the polymer chains were deposited on the MMT surface [37] and generated more cross-links. 

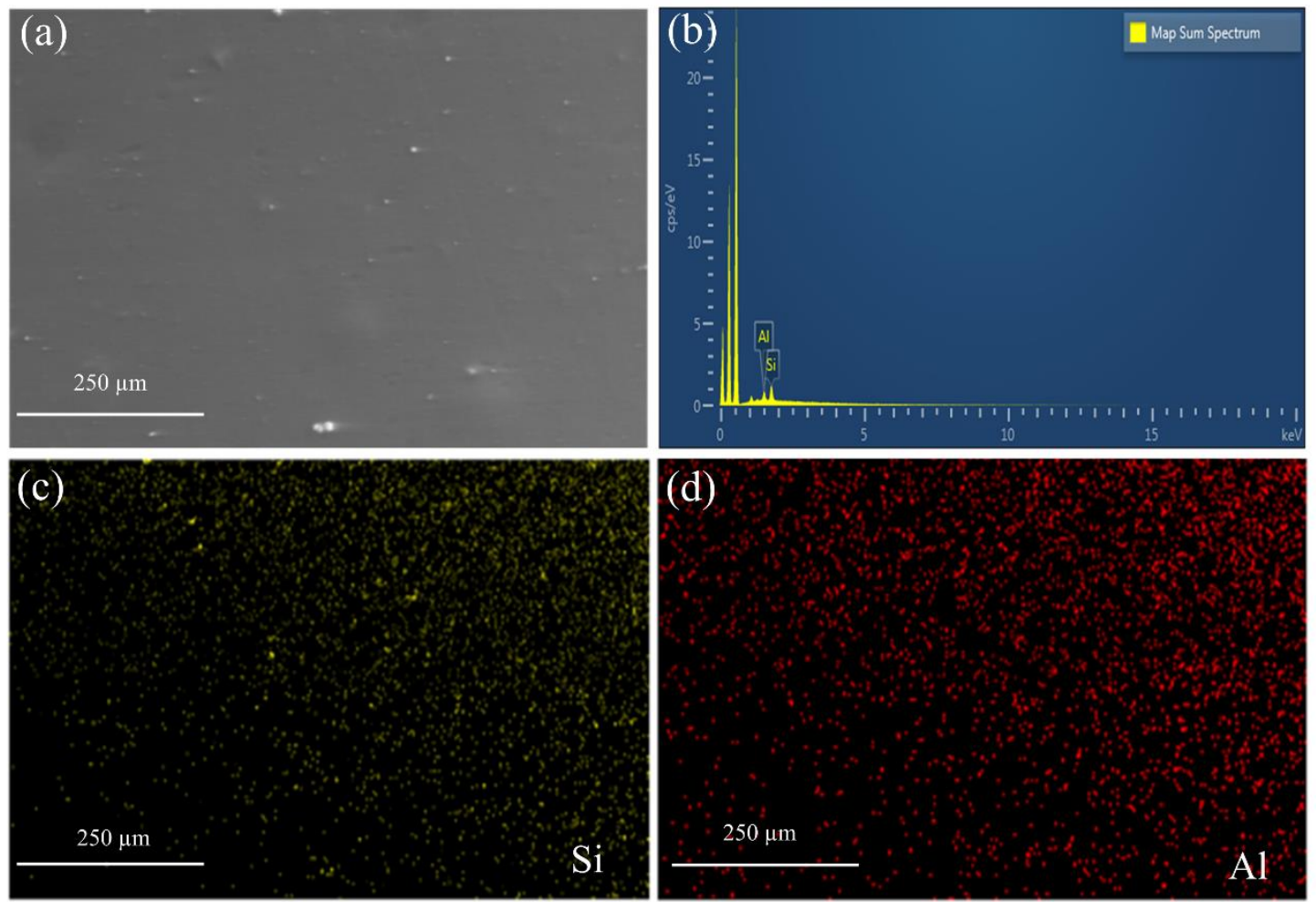

Figure 2. MMT distribution in P1C8M1 hydrogels at wet form at 800× magnification (a) SEM image; (b) EDS spectrum showing atomic proportions; (c) Si elemental mapping ; (d) Al elemental mapping.
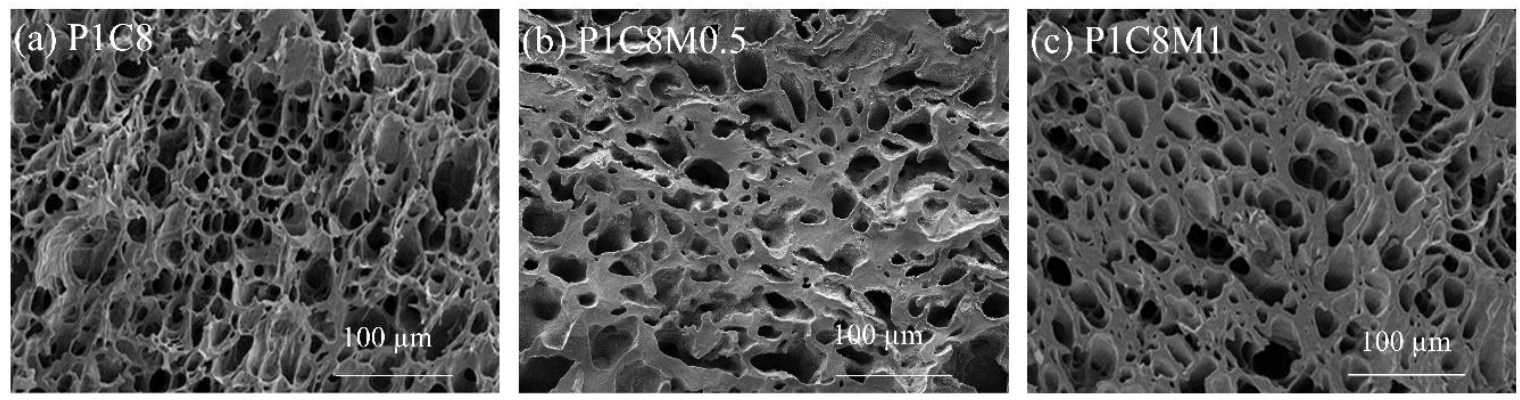

Figure 3. Cross-section images of hydrogels at dry form at 1000× magnification (a) P1C8; (b) P1C8M0.5; (c) P1C8M1.

\subsection{Tensile mechanical properties.}

The tensile strengths and Young's moduli of hydrogels are in Figure 4. Tensile strength of PC hydrogels varied insignificantly with PVA concentration, ranging from 35.1 to $40.3 \mathrm{kPa}$.

(a)

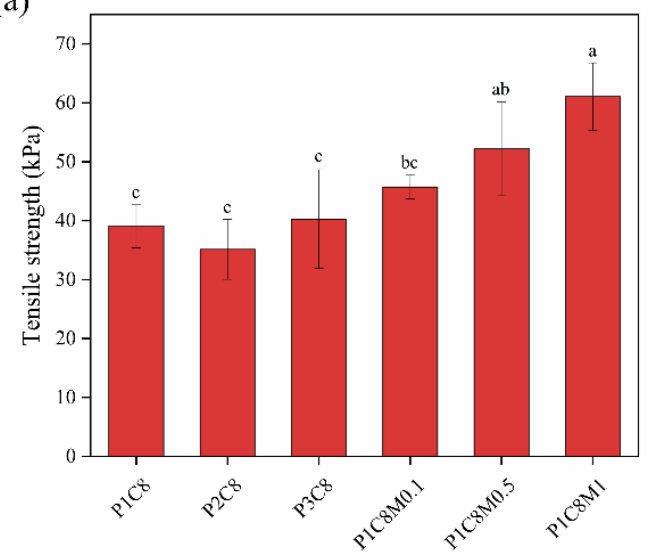

(b)

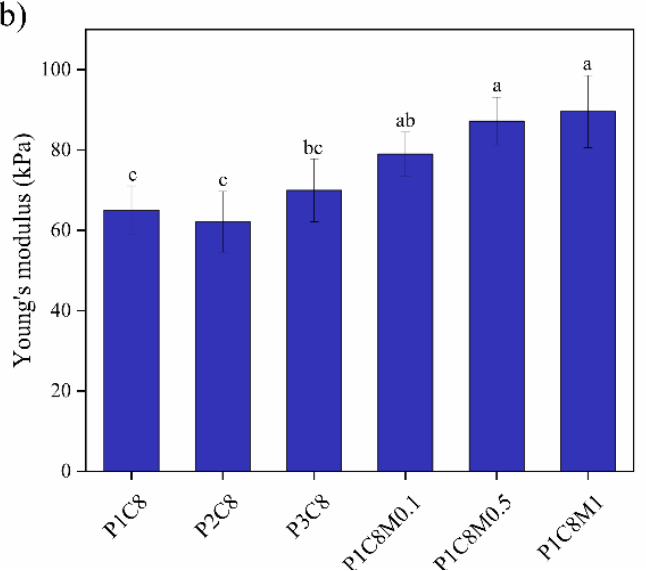

Figure 4. Tensile test of hydrogels (a) Tensile strength; (b) Young's modulus. 
However, the addition of MMT increased the tensile strength, which increased from $39.0 \mathrm{kPa}$ of P1C8 to $61.1 \mathrm{kPa}$ of P1C8M1: the polymer could anchor on the MMT surface through physical interactions, improving the tensile strength [37]. Young's moduli of the hydrogels had a similar tendency to tensile strength: they increased with added MMT from $65.0 \mathrm{kPa}$ of P1C8 to $89.6 \mathrm{kPa}$ of P1C8M1, whereas raising PVA content only slightly affected it $(62.1-69.9 \mathrm{kPa})$.

\subsection{Compressive mechanical properties.}

Figure 5 shows compressive strengths and moduli of the P1C8 hydrogels with increased MMT. The compressive strengths increased from $6.6 \mathrm{kPa}$ of P1C8 to $17.2 \mathrm{kPa}$ of P1C8M1. The compressive moduli of PCM hydrogels with 0.1-1\% MMT (64.7-103.6 kPa) were higher than that of PC hydrogel $(51.0 \mathrm{kPa})$. The MMT surface interacted with the polymer chains by hydrogen bond, which increased cross-linked density, resulting in higher strength [38]. Thus, MMT addition enhanced both tensile and compressive strength.

(a)

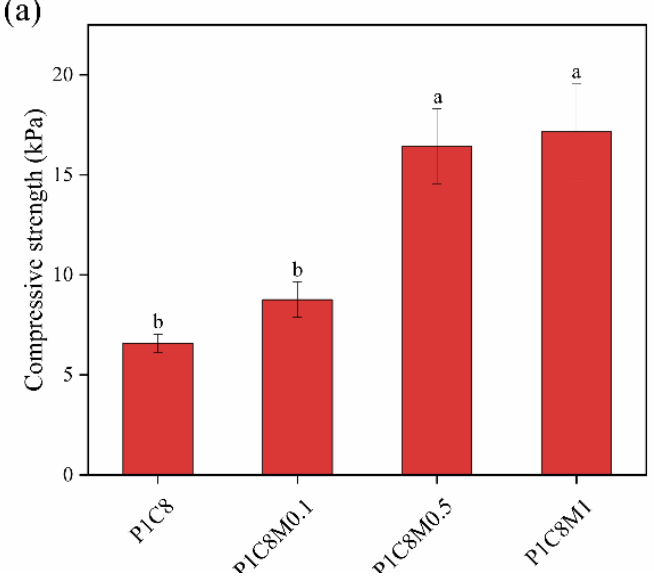

(b)

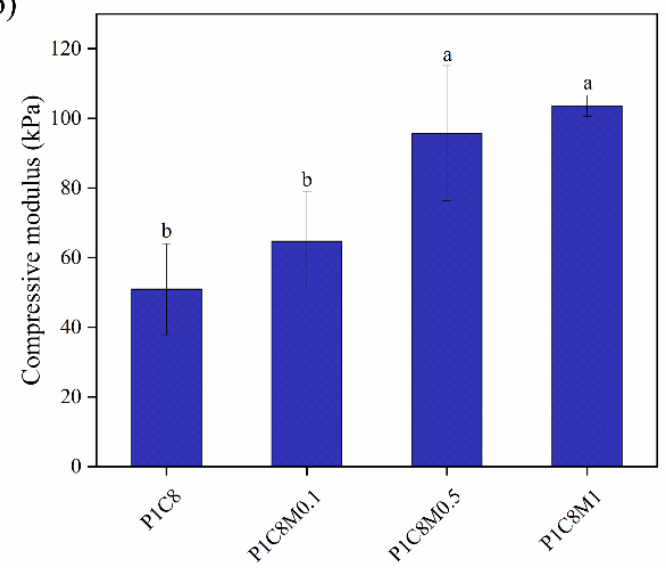

Figure 5. Compression of hydrogels (a) compressive strength; (b) compressive modulus.

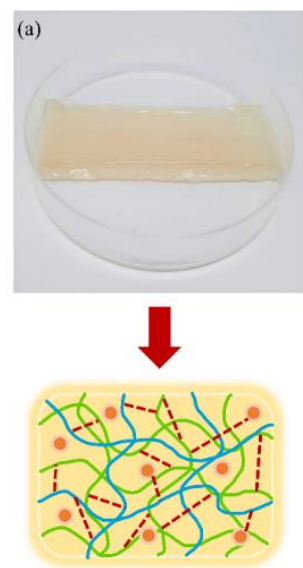

Original hydrogel
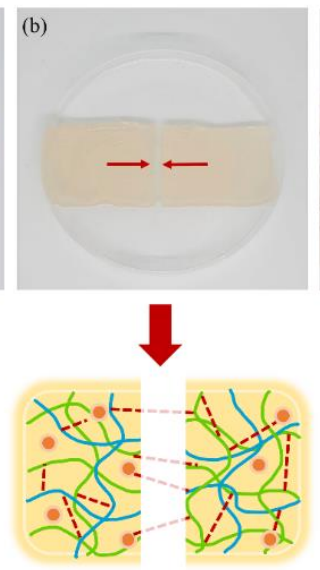

Hydrogel cut into two pieces
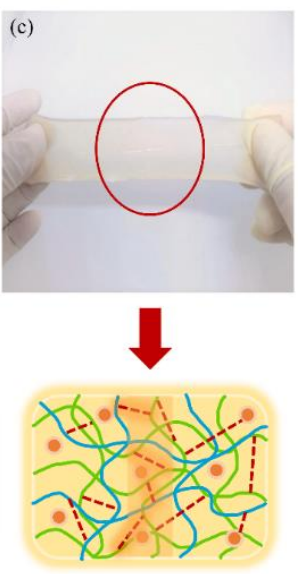

Healed hydrogel

$\mathrm{N}=\mathrm{CMC}$

$\Omega=$ PVA

--- $\quad=$ Hydrogen bond

$=\mathrm{MMT}$

Figure 6. Healing of P1C8M1 hydrogel: (a) original hydrogel; (b) hydrogel cut into two pieces; (c) stretching of the healed hydrogel; (d) images of the cut hydrogel at $0,1,5$, and 10 days. 


\subsection{Self-healing properties.}

Figure 6(a-c) shows the self-healing ability of PCM hydrogel (P1C8M1). The hydrogel was cut into two pieces by a scalpel and then reattached to each other without a healing agent. The hydrogel was stored in a $90 \pm 5 \%$ relative humidity atmosphere. After 10 days, the two pieces of hydrogels merged, and they could be stretched and bent without any cracks. The images in Figure 6d monitored the crack healing over10 days. The cut was completely combined within 10 days, confirming the hydrogel self-healing ability.

To assess self-healing efficiency, tensile strengths were measured. Figure 7(a) displays stress-strain curves of original and healed hydrogels (P1C8 and P1C8M1). The original uncut P1C8M1 hydrogel showed a tensile strength of $61.1 \mathrm{kPa}$ while the healed hydrogel showed $56.7 \mathrm{kPa}$, i.e., the cut gel regained $\sim 93 \%$ of its original strength, whereas the P1C8 hydrogel, without MMT, only recovered $60 \%$ of its strength of $23.5 \mathrm{kPa}$. Thus, MMT addition significantly improved healing efficiency. Figure 7(b) shows the healing efficiency of all hydrogels. The PC hydrogels with increased PVA content (1-3\%) showed lower healing efficiency from $60.2 \%$ to $28.7 \%$, due to suppression of the polymer chains mobility, as suggested by Zhu et al. for acrylamide-based hydrogels [39]. MMT in the hydrogels significantly enhanced the healing efficiency, increasing from $79.6 \%$ at $0.1 \%$ MMT to $92.8 \%$ with $1 \%$ MMT. Long free polymer chains formed by hydrogen bonds between MMT silanol groups and polymer hydroxyl groups, i.e., PVA and CMC, were reconstituted after the damage, improving the self-healing ability [19, 40].

(a)

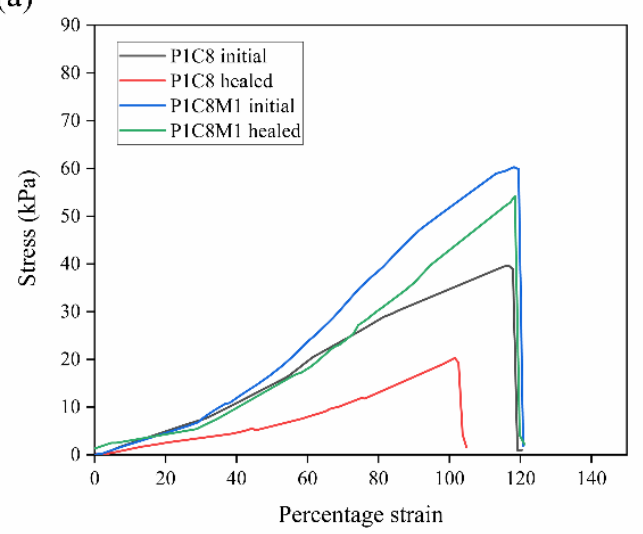

(b)

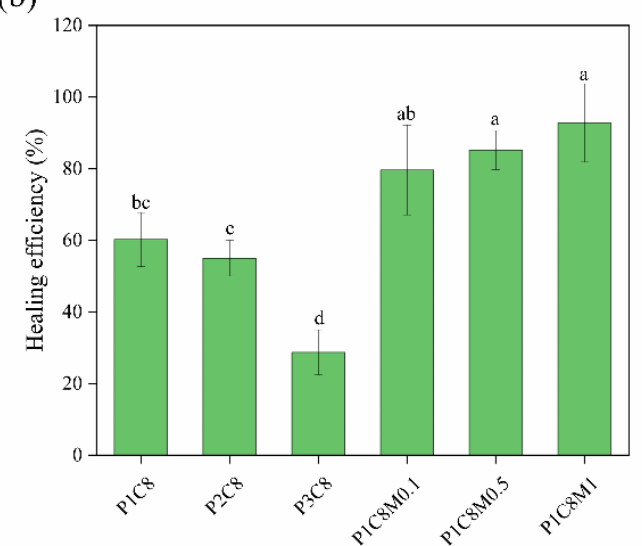

Figure 7. (a) Stress-strain curves of P1C8 and P1C8M1 hydrogels; (b) Hydrogel healing efficiency. Identical labels attached to the error bars indicate insignificant differences, $p<0.05$.

\subsection{Cytotoxicity test.}

Cytotoxicity tests, which checked cell viability of P1C8, P1C8M0.5, and P1C8M1 hydrogels, with different MMT content, are shown in Figure 8. The cell viabilities were 98.4\% for P1C8, $107.6 \%$ for P1C8M0.5 and $105.1 \%$ for P1C8M1. Values $>100 \%$ with MMT indicated cell growth in the hydrogel environment. ISO 10993-5 considers values $>70 \%$ indicate that the hydrogels were not toxic to Vero cells. Therefore, the hydrogels are safe for living cells. 


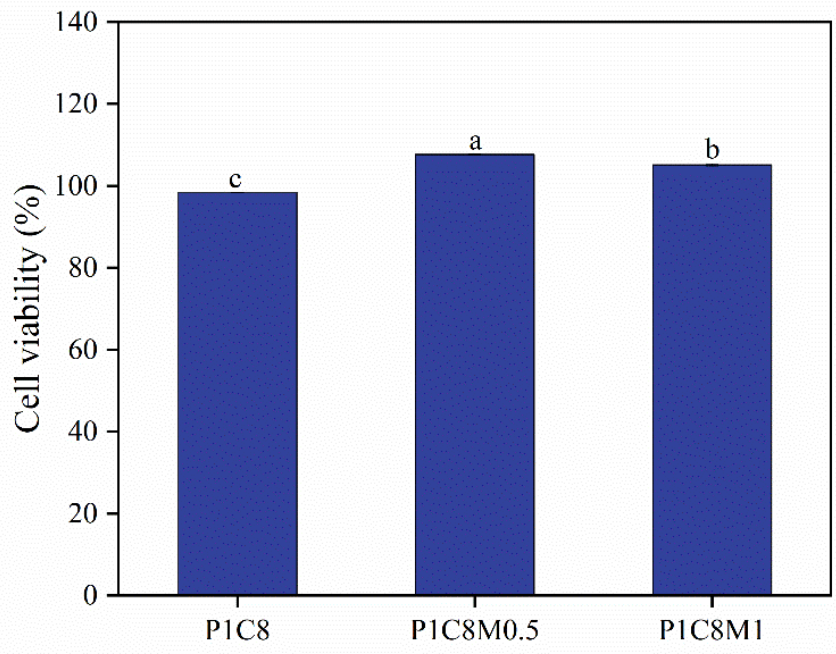

Figure 8. Hydrogel cell viability. Different labels "a-c" indicate significant differences $(\mathrm{p}<0.05)$.

\section{Conclusions}

Self-healing hydrogels, based on carboxymethyl cellulose/poly(vinylalcohol)/ montmorillonite by acidifying with citric acid showed good montmorillonite distribution, which caused thicker pore walls and improved mechanical properties, whereas PVA content did not significantly strengthen them. The hydrogels could completely self-heal within 10 days, caused by hydrogen bonds between the three components. The PCM hydrogels, with montmorillonite, exhibited good self-healing and recovered up to $93 \%$ of their strength, whereas a hydrogel, without montmorillonite, only recovered $60 \%$. However, increasing the PVA content decreased the healing efficiency. Moreover, the hydrogels were not toxic - the PCM hydrogel passed an initial test for safety in medical applications.

\section{Funding}

This research was funded by King Mongkut's Institute of Technology Ladkrabang.

\section{Acknowledgments}

The authors would like to thank the Scientific Instruments Center, School of Science, King Mongkut's Institute of Technology Ladkrabang for SEM and cytotoxicity testing.

\section{Conflicts of Interest}

The authors declare no conflict of interest.

\section{References}

1. Miyata, T. Preparation of smart soft materials using molecular complexes. Polym J 2010, 42, 277-289, https://doi.org/10.1038/pj.2010.12.

2. Shehata, N.; Abdelkareem, M. A.; Sayed, E. T.; Egirani, D. E.; Opukumo, A. W. Smart Materials: The Next Generation. In Reference Module in Materials Science and Materials Engineering Elsevier: Amsterdam, 2021.

3. Ghosal, A.; Kaushik, A. Intelligent Hydrogels in Diagnostics and Therapeutics. CRC Press: Boca Raton, 2020.

4. Zhao, H.; Liu, M.; Zhang, Y.; Yin, J.; Pei, R. Nanocomposite hydrogels for tissue engineering applications. Nanoscale 2020, 12, 14976-14995, https://doi.org/10.1039/D0NR03785K. 
5. Chalitangkoon, J.; Wongkittisin, M.; Monvisade, P. Silver loaded hydroxyethylacryl chitosan/sodium alginate hydrogel films for controlled drug release wound dressings. Int J Biol Macromol 2020, 159, 194203, https://doi.org/10.1016/j.ijbiomac.2020.05.061.

6. Alvarez-Lorenzo, C.; Grinberg, V. Y.; Burova, T. V.; Concheiro, A. Stimuli-sensitive cross-linked hydrogels as drug delivery systems: Impact of the drug on the responsiveness. Int J Pharm 2020, 579, 119157 , https://doi.org/10.1016/j.ijpharm.2020.119157.

7. Muchová, M.; Münster, L.; Capáková, Z.; Mikulcová, V.; Kưritka, I.; Vícha, J. Design of dialdehyde cellulose cross-linked poly(vinyl alcohol) hydrogels for transdermal drug delivery and wound dressings. Mater Sci Eng C 2020, 116, 111242, https://doi.org/10.1016/j.msec.2020.111242.

8. Hu, N.; Lin, L.; Tan, J.; Wang, W.; Lei, L.; Fan, H.; Wang, J.; Müller-Buschbaum, P.; Zhong, Q. Wearable Bracelet Monitoring the Solar Ultraviolet Radiation for Skin Health Based on Hybrid IPN Hydrogels. ACS Appl Mater Interfaces 2020, 12, 56480-56490, https://doi.org/10.1021/acsami.0c17628.

9. Wei, J.; Xie, J.; Zhang, P.; Zou, Z.; Ping, H.; Wang, W.; Xie, H.; Shen, J. Z.; Lei, L.; Fu, Z. Bioinspired 3D Printable, Self-Healable, and Stretchable Hydrogels with Multiple Conductivities for Skin-like Wearable Strain Sensors. ACS Appl Mater Interfaces 2021, 13, 2952-2960, https://doi.org/10.1021/acsami.0c19512.

10. Taylor, D. L.; in het Panhuis, M. Self-Healing Hydrogels. Adv Mater 2016, 28, 9060-9093, https://doi.org/10.1002/adma.201601613.

11. Li, D.-q.; Wang, S.-y.; Meng, Y.-j.; Guo, Z.-w.; Cheng, M.-m.; Li, J. Fabrication of self-healing pectin/chitosan hybrid hydrogel via Diels-Alder reactions for drug delivery with high swelling property, $\mathrm{pH}-$ responsiveness, and cytocompatibility. Carbohydr Polym 2021, 268, 118244, https://doi.org/10.1016/j.carbpol.2021.118244.

12. Zhao, D.; Feng, M.; Zhang, L.; He, B.; Chen, X.; Sun, J. Facile synthesis of self-healing and layered sodium alginate/polyacrylamide hydrogel promoted by dynamic hydrogen bond. Carbohydr Polym 2021, 256, 117580, https://doi.org/10.1016/j.carbpol.2020.117580.

13. Shin, S.-H.; Lee, W.; Kim, S.-M.; Lee, M.; Koo, J. M.; Hwang, S. Y.; Oh, D. X.; Park, J. Ion-conductive selfhealing hydrogels based on an interpenetrating polymer network for a multimodal sensor. Chem Eng J 2019, 371, 452-460, https://doi.org/10.1016/j.cej.2019.04.077.

14. Jiang, H.; Duan, L.; Ren, X.; Gao, G. Hydrophobic association hydrogels with excellent mechanical and selfhealing properties. Eur Polym J 2019, 112, 660-669, https://doi.org/10.1016/j.eurpolymj.2018.10.031.

15. Ye, J.; Fu, S.; Zhou, S.; Li, M.; Li, K.; Sun, W.; Zhai, Y. Advances in hydrogels based on dynamic covalent bonding and prospects for its biomedical application. Eur Polym J 2020, 139, 110024, https://doi.org/10.1016/j.eurpolymj.2020.110024.

16. Zhang, H.; Zhai, D.; He, Y. Graphene oxide/polyacrylamide/carboxymethyl cellulose sodium nanocomposite hydrogel with enhanced mechanical strength: preparation, characterization and the swelling behavior. RSC Adv 2014, 4, 44600-44609, https://doi.org/10.1039/C4RA07576E.

17. Park, C.; Kim, G.; Jung, J.; Krishnakumar, B.; Rana, S.; Yun, G. J. Enhanced self-healing performance of graphene oxide/vitrimer nanocomposites: A molecular dynamics simulations study. Polymer 2020, 206, 122862, https://doi.org/10.1016/j.polymer.2020.122862.

18. Niu, J.; Wang, J.; Dai, X.; Shao, Z.; Huang, X. Dual physically cross-linked healable polyacrylamide/cellulose nanofibers nanocomposite hydrogels with excellent mechanical properties. Carbohydr Polym 2018, 193, 73-81, https://doi.org/10.1016/j.carbpol.2018.03.086.

19. Haraguchi, K.; Uyama, K.; Tanimoto, H. Self-healing in Nanocomposite Hydrogels. Macromol Rapid Commun 2011, 32, 1253-8, https://doi.org/10.1002/marc.201100248.

20. Uddin, F. Montmorillonite: An introduction to properties and utilization. IntechOpen: London, 2018; pp. 123.

21. Kaemkit, C.; Monvisade, P.; Siriphannon, P.; Nukeaw, J. Water-Soluble Chitosan Intercalated Montmorillonite Nanocomposites for Removal of Basic Blue 66 and Basic Yellow 1 from Aqueous Solution. J Appl Polym Sci 2013, 128, https://doi.org/10.1002/app.38255.

22. Lawchoochaisakul, S.; Monvisade, P.; Siriphannon, P. Cationic starch intercalated montmorillonite nanocomposites as natural based adsorbent for dye removal. Carbohydr Polym 2021, 253, 117230, https://doi.org/10.1016/j.carbpol.2020.117230.

23. Qi, X.; Guan, Y.; Chen, G.; Zhang, B.; Ren, J.; Peng, F.; Sun, R. A non-covalent strategy for montmorillonite/xylose self-healing hydrogels. RSC Adv 2015, 5, 41006-41012, https://doi.org/10.1039/C5RA04115E.

24. Li, W.; Liu, J.; Liang, B.; Shu, Y.; Wang, J. Small molecule hydrogen-bonded toughen nacre-inspired montmorillonite-konjac glucomannan-glycerin film with superior mechanical, transparent and UV-blocking properties. Compos B Eng 2021, 204, 108492, https://doi.org/10.1016/j.compositesb.2020.108492.

25. Akalin, G.; Pulat, M. Preparation and Characterization of Nanoporous Sodium Carboxymethyl Cellulose Hydrogel Beads. J Nanomater 2018, 2018, 1-12, https://doi.org/10.1155/2018/9676949.

26. Rahman, M. S.; Hasan, M. S.; Nitai, A. S.; Nam, S.; Karmakar, A. K.; Ahsan, M. S.; Shiddiky, M. J. A.; Ahmed, M. B. Recent Developments of Carboxymethyl Cellulose. Polymers 2021, 13, 1345, https://doi.org/10.3390/polym13081345. 
27. Zheng, W. J.; Gao, J.; Wei, Z.; Zhou, J.; Chen, Y. M. Facile fabrication of self-healing carboxymethyl cellulose hydrogels. Eur Polym J 2015, 72, 514-522, https://doi.org/10.1016/j.eurpolymj.2015.06.013.

28. Chen, Y. M.; Sun, L.; Yang, S. A.; Shi, L.; Zheng, W. J.; Wei, Z.; Hu, C. Self-healing and photoluminescent carboxymethyl cellulose-based hydrogels. Eur Polym J 2017, 94, 501-510, https://doi.org/10.1016/j.eurpolymj.2017.06.008.

29. Tarus, D.; Hachet, E.; Messager, L.; Catargi, B.; Ravaine, V.; Auzély-Velty, R. Readily prepared dynamic hydrogels by combining phenyl boronic acid- and maltose-modified anionic polysaccharides at neutral $\mathrm{pH}$. Macromol Rapid Commun 2014, 35, 2089-95, https://doi.org/10.1002/marc.201400477.

30. Tamahkar, E. Bacterial cellulose/poly vinyl alcohol based wound dressings with sustained antibiotic delivery. Chem Pap 2021, 75, 3979-3987, https://doi.org/10.1007/s11696-021-01631-w.

31. Li, S.; Zhou, D.; Pei, M.; Zhou, Y.; Xu, W.; Xiao, P. Fast gelling and non-swellable photopolymerized poly (vinyl alcohol) hydrogels with high strength. Eur Polym J 2020, 134, 109854, https://doi.org/10.1016/j.eurpolymj.2020.109854.

32. Chen, J.; Yang, Z.; Shi, D.; Zhou, T.; Kaneko, D.; Chen, M. High strength and toughness of double physically cross-linked hydrogels composed of polyvinyl alcohol and calcium alginate. J Appl Polym Sci 2021, 138, 49987, https://doi.org/10.1002/app.49987.

33. Ding, F.; Zou, Y.; Wu, S.; Zou, X. Self-healing and tough hydrogels with conductive properties prepared through an interpenetrating polymer network strategy. Polymer 2020, 206, 122907, https://doi.org/10.1016/j.polymer.2020.122907.

34. Sathain, A.; Monvisade, P.; Siriphannon, P. Bioactive alginate/carrageenan/calcium silicate porous scaffolds for bone tissue engineering. Mater Today Commun 2021, 26, 102165 , https://doi.org/10.1016/j.mtcomm.2021.102165.

35. Xiao, C.; Gao, Y. Preparation and properties of physically cross-linked sodium carboxymethylcellulose/poly(vinyl alcohol) complex hydrogels. J Appl Polym Sci 2008, 107, 1568-1572, https://doi.org/10.1002/app.27203.

36. Zahedi, Y.; Fathi-Achachlouei, B.; Yousefi, A. R. Physical and mechanical properties of hybrid montmorillonite/zinc oxide reinforced carboxymethyl cellulose nanocomposites. Int J Biol Macromol 2018, 108, 863-873, https://doi.org/10.1016/j.ijbiomac.2017.10.185.

37. Zhou, Q.; Li, Y.; Liu, H.; Li, X. Tough nanocomposite hydrogel based on montmorillonite nanosheets/acrylic acid/acrylamide with copper removal properties. Colloids Surf A Physicochem Eng Asp 2020, 598, 124836, https://doi.org/10.1016/j.colsurfa.2020.124836.

38. Mohd, S. S.; Abdullah, M. A. A.; Mat Amin, K. A. Gellan gum/clay hydrogels for tissue engineering application: Mechanical, thermal behavior, cell viability, and antibacterial properties. J Bioact Compat Polym 2016, 31, 648-666, https://doi.org/10.1177/0883911516643106.

39. Zhu, J.; Guo, P.; Chen, D.; Xu, K.; Wang, P.; Guan, S. Fast and excellent healing of hydroxypropyl guar gum/poly(N,N-dimethyl acrylamide) hydrogels. J Polym Sci, Part B: Polym Phys 2018, 56, 239-247, https://doi.org/10.1002/polb.24514.

40. Hammoudi, N.; Ziani Cherif, H.; Borsali, F.; Benmansour, K.; Meghezzi, A. Preparation of active antimicrobial and antifungal alginate-montmorillonite/lemon essential oil nanocomposite films. Mater Technol 2020, 35, 383-394, https://doi.org/10.1080/10667857.2019.1685292. 